2. F. P. Ramsey, On a problem of formal logic, Proc. London Math. Soc. (2) 30 (1930), 264-286.

Dartmouth College

\title{
COUNTEREXAMPLE TO EULER'S CON JECTURE ON SUMS OF LIKE POWERS
}

BY L. J. LANDER AND T. R. PARKIN

Communicated by J. D. Swift, June 27, 1966

A direct search on the CDC 6600 yielded

$$
27^{5}+84^{5}+110^{5}+133^{5}=144^{5}
$$

as the smallest instance in which four fifth powers sum to a fifth power. This is a counterexample to a conjecture by Euler [1] that at least $n n$th powers are required to sum to an $n$th power, $n>2$.

\section{REFERENCE}

1. L. E. Dickson, History of the theory of numbers, Vol. 2, Chelsea, New York, 1952, p. 648. 